(C) 2013 Institute of Metals, Minerals and Mining

This document is published in:

Neves, R. G.; Ferrari, B.; Sánchez-Herencia, A. J.; Gordo, E. Improvement of sintering behaviour of titanium by colloidal techniques, Power Metallurgy, Volume 56, Number 4, September 2013 , pp. 258-262(5) (2013), 258-262(5).

DOI: $\underline{\text { http://dx.doi.org/10.1179/0032589913Z.000000000117 }}$ 


\title{
Improvement of sintering behaviour of titanium by colloidal techniques
}

\author{
R. G. Neves ${ }^{* 1}$, B. Ferrari ${ }^{2}$, A. J. Sanchez-Herencia ${ }^{2}$ and E. Gordo ${ }^{1}$
}

The conventional sintering of titanium requires high temperatures to obtain high densities and low porosity, giving rise to microstructures with high grain size, and high interstitial contents, both of which adversely affect the mechanical properties obtained. A novel approach is reported which uses fine $(10 \mu \mathrm{m})$ spherical Ti powder to improve the sintering behaviour, together with a small percentage of alumina particles $(0.5 \mu \mathrm{m})$ to restrict grain growth. Colloidal techniques were used to form spherical agglomerates, 50-300 $\mu \mathrm{m}$ in size, of Ti powder with alumina particles dispersed homogenously on the $\mathrm{Ti}$ surface. These agglomerates present good compressibility and make it possible to sinter effectively at low temperatures, increasing the relative density and decreasing grain size.

Conventional PM processing via pressing and sintering presents some difficulties for titanium, due to the low strain capacity of the Ti hexagonal structure at room temperature, and its high reactivity, ${ }^{1,2}$ which lead to low compressibility. Compressibility is usually worse for powders of small particle size. It has been reported that sintering temperatures up to $1350^{\circ} \mathrm{C}$, with a minimum temperature of $1250^{\circ} \mathrm{C}$, and times as long as $2-4 \mathrm{~h}$, were necessary for titanium to obtain sintering densities of $\sim 95 \%$ of theoretical. ${ }^{3-5}$ As a consequence, microstructural coarsening occurs, the content of interstitials is high, and the final properties of the materials are less good than expected. These detrimental features could be mitigated by reducing the sintering temperature, which can be achieved by reducing the particle

${ }^{1}$ Departamento de Ciencia e Ingeniería de Materiales e Ingeniería Química, Universidad Carlos III de Madrid, Avda. Universidad, 30 28911 Leganés, Madrid, Spain

${ }^{2}$ Instituto de Cerámica y Vidrio, CSIC, c/Kelsen 5, 28049 Madrid, Spain

*Corresponding author, email rgneves@ing uc3m.es. size of the initial powders. Moreover, grain growth during sintering could be avoided by the addition of a small percentage of ceramic particles to pin grain boundaries, and hence provide better control of the mechanical properties. The addition of small ceramics particles would also modify the elastic modulus and improve the wear resistance. ${ }^{6,7}$ However, fine powders are difficult to process by PM techniques owing to their poor flow properties and compressibility.

Spray drying is commonly employed to transform small powders into granules with improved flow, die filling and pressing properties. It involves dispersion of the powders in a liquid medium, usually water, that is sprayed through a nozzle and dried by a hot air current. The colloidal chemistry of the powders dispersed in water is critical to achieve homogenous materials. Spray drying has long been used in ceramics processing to achieve complex shapes and microstructures. ${ }^{8,9}$ The colloidal processing of powders dispersed in water is based on two main interconnected factors. First, control of the interparticle potentials to achieve high repulsions, prevent agglomeration and obtain good dispersion; and, second, the rheology of the slurries, which depends on the level of repulsion of the particles in the medium as well as on other variables such as solids content and processing additives. By controlling the colloid chemistry of metallic particles in water, suspensions of pure nickel and nickel-ceramic composites with high solids contents have been obtained. ${ }^{10,11}$ Using the colloidal technique, stable aqueous suspensions of $\mathrm{Ti}$ in water without and with alumina particles dispersed homogenously on Ti surfaces were obtained, which were spray dried in order to obtain agglomerates. These agglomerates were pressed and sintered. In this work, the sintering behaviour of titanium agglomerate powders without and with a small percent of alumina particles was studied and the density, porosity, grain size and hardness of sintered materials were determined.

\section{Experimental procedure}

Two spherical elemental titanium powders with different particle sizes (45 and $10 \mu \mathrm{m}$, hereafter referred to Ti45 and Ti10), supplied by AP\&C Inc., were used as starting materials. The alumina powder, supplied by Condea HPA05, USA, had a high purity of 99.99\% and was presented as alpha phase. It had an irregular shape with a mean particle size of $0.5 \mu \mathrm{m}$ and a specific surface area of $9.5 \mathrm{~m}^{2} \mathrm{~g}^{-1}$. The size and morphology of all powders were examined by FE-SEM (Hitachi S4700 microscope, Japan). Density and particle size distribution and specific surface area were measured using respectively a Monosorb

Multipycnometer and Mastersizer S (Malvern Instruments Ltd) and a Monosorb Surface Area

(Quantachrome Corp., USA). Oxygen content was determined with a Leco TCH-600.

A zeta potential $(\zeta)$ technique (ZetaMeter 3.0+, Zeter Meter Inc., EEUU) was employed to study the surface characteristics of the initial powders This technique is commonly employed in colloidal processing, which permits the creation of stable suspensions in an aqueous environment to measure the potential of the particles in solutions at different $\mathrm{pH}$ values and dispersant concentrations. The optimal value to produce repulsion of the particles and thus ensure correct dispersion is above $\pm 30 \mathrm{mV}$. To produce the spray dried agglomerate powders, slurries of Ti10 having high solid contents (up to 50 vol.-\%) with alumina particle additions (1 wt-\%) were fabricated in water using ammonium polyacrylate as dispersant. After the powder was added to the water with the dispersant, high power ultrasonic aggitation (400 W) was applied to break up undesirable agglomerates and the slurries were stirred for $1 \mathrm{~h}$. Polyvinyl 
alcohol (PVA, Aldrich) and polyethylene glycol (PEG, Aldrich) were used as binders. The $\mathrm{pH}$ was measured $(691$ $\mathrm{pH}$ meter, Metrohm) and adjusted by using HTMA (tetra-methyl ammonium hydroxide) and dilute $\mathrm{HNO}_{3}$ solutions. The rheological behaviour of the suspensions was determined with a viscometer (Rotovisco RV 20, Haake) using a concentric cylinders system (MV2). Suspensions were spray dried using a Labplant SD-05. The operating parameters (temperatures at the inlet $\left(220^{\circ} \mathrm{C}\right)$ and exhaust $\left(100^{\circ} \mathrm{C}\right)$, slurry pump rate $\left(2 \mathrm{~L} \mathrm{~h}^{-1}\right)$, air flowrate $\left(38 \mathrm{~m}^{3} \mathrm{~h}^{-1}\right)$ and atomising nozzle design) were set to provide spherical agglomerates. Both the Ti45 powders and the agglomerates formed from suspensions of Ti10 powders were processed by pressing and sintering. Pressing was performed in a die using a double-action uniaxial press to produce cylinders $16 \mathrm{~mm}$ in diameter. The green compacts were sintered in vacuum at $1100^{\circ} \mathrm{C}$ for $30 \mathrm{~min}$. The green density was calculated from the dimensions and mass, whereas sintered density was measured using both dimensions and the Multipycnometer to obtain values of total, closed and open porosity. The microstructures were examined using optical microscopy and grain size measurements obtained by image analysis using Analysis get IT 5.0 software. Several zones of each sample were analysed to obtain a mean grain size. Finally, hardness was measured with a universal hardness tester (Wilson Wolpert), using a $30 \mathrm{~kg}$ load. Tests were carried out on the transversal sections of samples and an average of five measurements for each sample was obtained.

\section{Results and discussion}

The main characteristics of the titanium powders are reported in Table 1. As expected, the Ti10 powder presents higher specific surface area because of its smaller particle size. Equivalent spherical diameter $d_{\mathrm{BET}}$ calculated from the specific surface area is similar to that measured by diffraction techniques (Mastersizer), indicating that powders are highly spherical with a smooth surface. Both powders present similar density, very close to the theoretical. Oxygen content was unexpectedly higher in the powder with the lower surface area.

The zeta potential was measured at different $\mathrm{pH}$ values to determine the surface behaviour of the materials and establish the conditions for maximum dispersion. However, control of the $\mathrm{pH}$ is not sufficient to ensure a stable dispersion: it can produce fluctuations and destabilise the slurries, thus polyelectrolyte (PAA) was used to provide additional stabilisation. According to previous work in the authors' group, suspensions of Ti45 and Ti10 have the same behaviour, being stabilised in the range $\mathrm{pH6}-10$. The use of PAA to provide an electrostatic dispersion mechanism gives the Ti10 suspension better stability and dispersion compared with the Ti45 suspension. The rheological study defined the conditions required to achieve stable slurries with solids contents up to 50 vol.- $\%$ and viscosity sufficiently low to ensure continuous feeding of the spray drying nozzle. Fo 50 vol. $-\%$ Ti10 slurries at $\mathrm{pH}=10,1 \%$ PAA, and $2 \%$ PVA provided spray dried powders with the best features for pressing and sintering; the same conditions applied with $1 \mathrm{wt}-\%$ alumina additions. It can be seen in Fig. $1 a$ that spherical agglomerates of Ti10 with alumina particles produced under these conditions have regular shapes and are between 50 and $300 \mu \mathrm{m}$ in diameter. The particle size distribution of these agglomerates is shown in Fig. $1 b$ and Fig. $1 c$ shows the alumina particles to be dispersed homogeneously on the Ti surfaces.

The compressibility of the Ti45 powder (as received) and spray dried Ti10 powder agglomerates without and with alumina particles was studied. Compressibility curves are shown in Fig. 2. It can be observed that the green density is higher for pressed Ti10 agglomerates than for Ti45 powder, owing to the better particle size distribution and close packing achieved with the agglomerates. The Ti10 agglomerates without alumina present better compressibility than agglomerates with alumina particles; it is assumed that the hard alumina particles act as inclusions to increase the yield stress. A compaction pressure of $600 \mathrm{MPa}$ was selected for the further work; specimens were pressed and sintered at $1100^{\circ} \mathrm{C}$ for $30 \mathrm{~min}$.

Density, porosity and mean grain size results for the sintered samples are summarised in Table 2. It is observed that specimens from the spray dried agglomerates show a lower open porosity than the Ti45 specimens. The Ti10 specimens with alumina shows a lower closed porosity than the other specimens. The two agglomerates have similar total porosity but the addition of alumina powder reduces closed porosity and increases the open porosity. After sintering, an increase of the oxygen content with respect to the as received powders is observed in all cases and is highest for the spray-dried powder with alumina. Oxygen pick-up occurs during all processing steps and remains within the sample even after sintering under high vacuum. It appears that the use of agglomerated powder increases density and decreases total porosity. The addition of alumina particles makes it possible to reach density values close to $99 \%$ and a reduction of porosity at temperatures as low as $1100^{\circ} \mathrm{C}$.

It can be seen in Fig. 3 that the microstructure of the sintered materials consisted in all cases of equiaxed grains of alpha phase plus pores. The grain size of the Ti45 specimen is larger than that of Ti10 without or with alumina particles. Several images of each material were subjected to image analysis to determine the mean grain size. A reduction of $40 \%$ relative to Ti 45 is observed for Ti10 powder without alumina and a reduction of $56 \%$ for Ti10 powder with alumina. The fraction of porosity is higher and more uniformly distributed in Ti45 (small round dots in each grain), whereas the Ti10 specimens without and with

Table 1 Characteristics of investigated powders (laboratory measurements)

\begin{tabular}{|c|c|c|c|c|c|}
\hline \multirow[b]{2}{*}{ Powder type } & \multicolumn{2}{|c|}{ Particle size $/ \mu \mathrm{m}$} & \multirow[b]{2}{*}{ Specific surface area $/ \mathrm{m}^{2} \mathrm{~g}^{-1}$} & \multirow[b]{2}{*}{ Density $/ \mathrm{g} \mathrm{cm}^{-3}$} & \multirow[b]{2}{*}{ O/[wt-\% } \\
\hline & {$\left[D_{\mathrm{v} 50}\right]$} & $d_{\mathrm{BET}}$ & & & \\
\hline $\begin{array}{l}\text { Ti45 } \\
\text { Ti10 }\end{array}$ & $\begin{array}{r}29 \cdot 21 \\
9 \cdot 93\end{array}$ & $\begin{array}{r}35 \cdot 0 \pm 0 \cdot 1 \\
7 \cdot 4+0 \cdot 1\end{array}$ & $\begin{array}{l}0.04 \pm 0.01 \\
0.17+0.01\end{array}$ & $\begin{array}{l}4 \cdot 4 \pm 0 \cdot 1 \\
4 \cdot 5+0 \cdot 1\end{array}$ & $\begin{array}{l}0.336 \\
0.216\end{array}$ \\
\hline
\end{tabular}




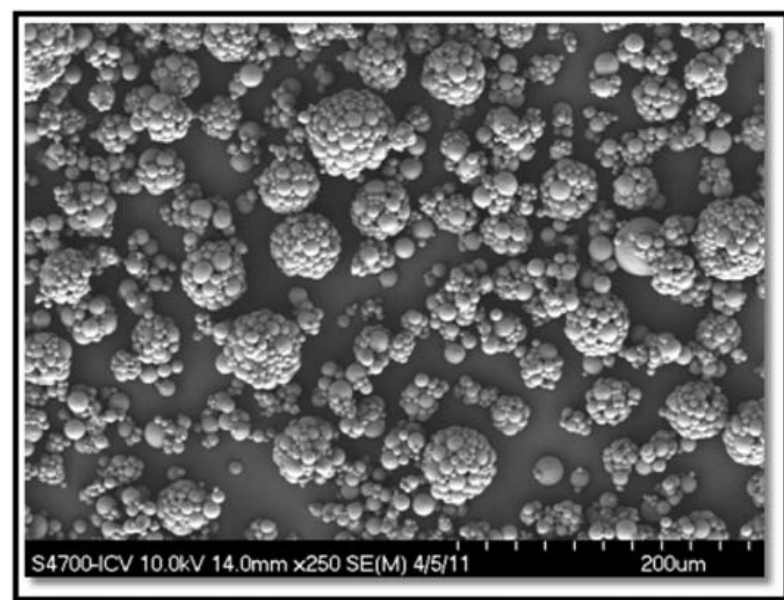

(a)

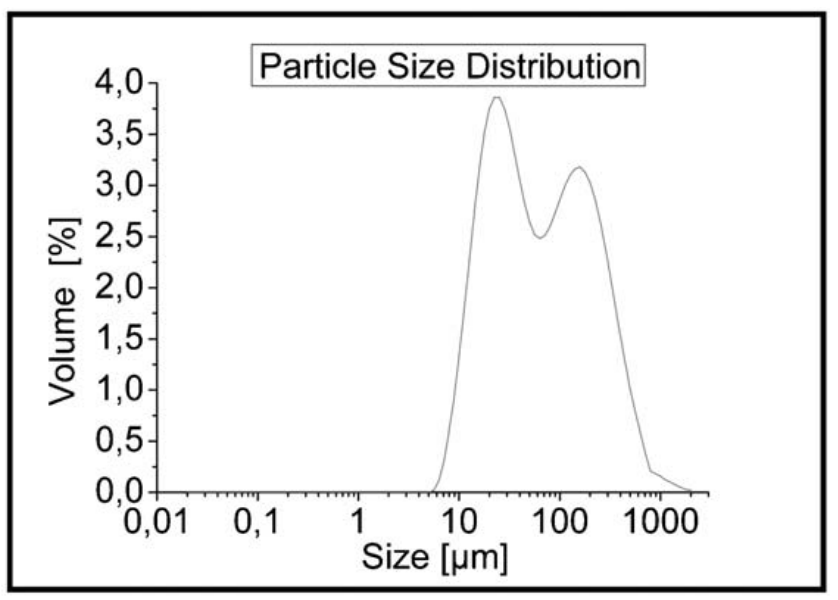

(b)

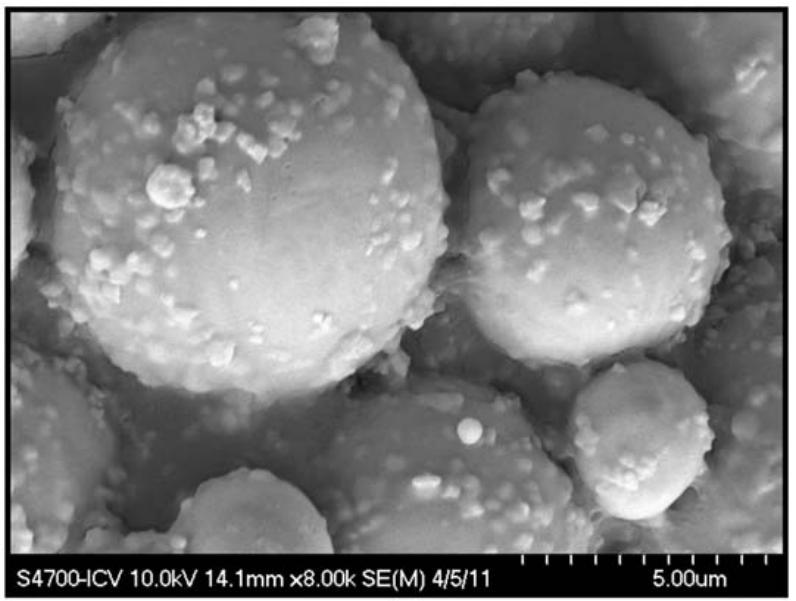

1 a Spherical agglomerates of Ti10 with alumina particles obtained by spray drying; b particle size distribution of agglomerates with alumina particles; $c$ alumina particles dispersed on $\mathrm{Ti}$ particle surfaces

alumina show similar porosity levels (in the alumina case visible as small round dots in the grain boundaries). These microstructures are in agreement with the results in Table 2, and confirm that smaller particle size improves the sinterability: the porosity is reduced for
Ti10 compared with Ti45. The addition of alumina particles decreases the grain size compared with agglomerated powder without alumina.

There are two factors that affect hardness values: oxygen content and grain size. It can be observed (Fig. 4)
ONLINE COLOUR ONLY

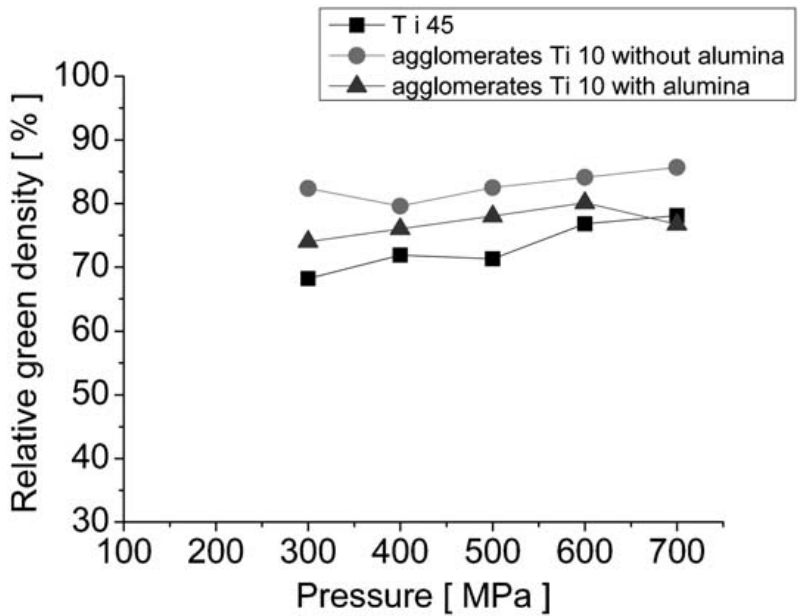

2 Compressibility of Ti45 titanium powder and Ti10 and Ti10 $+\mathrm{Al}_{2} \mathrm{O}_{3}$ agglomerates that the addition of alumina particles increases the hardness of the Ti10 specimens to values higher than those for Ti45 specimens, which could be due to the higher oxygen content that comes from alumina particles (Fig. 4), or the smaller grain size obtained. A further study is under way to clarify the respective effects of grain size, oxygen content and the alumina particles on the hardness and mechanical properties.

\section{Summary and conclusions}

Using a polyacrilate as dispersant, slurries of titanium particles of average particle size $10 \mu \mathrm{m}$ have been fabricated with a solids content up to 50 vol.-\%. With appropriate process parameters and addition of $2 \mathrm{wt}-\%$ PVA, the slurries can be spray dried to produce spherical agglomerates, with or without alumina particle additions, The alumina particles were dispersed homogeneously on the Ti particle 


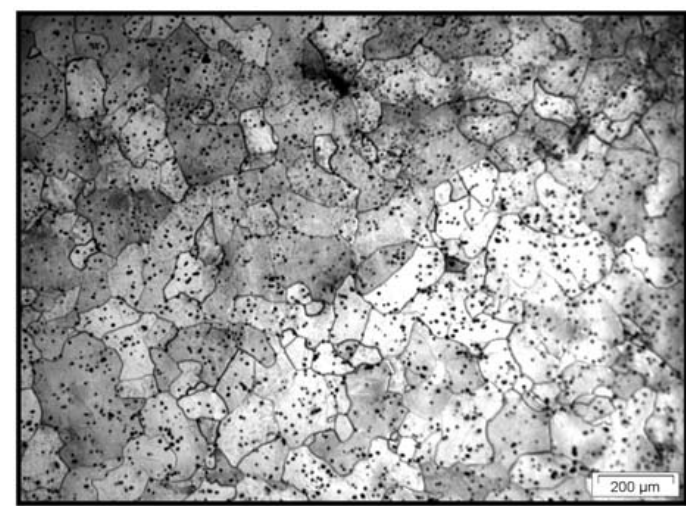

(a)

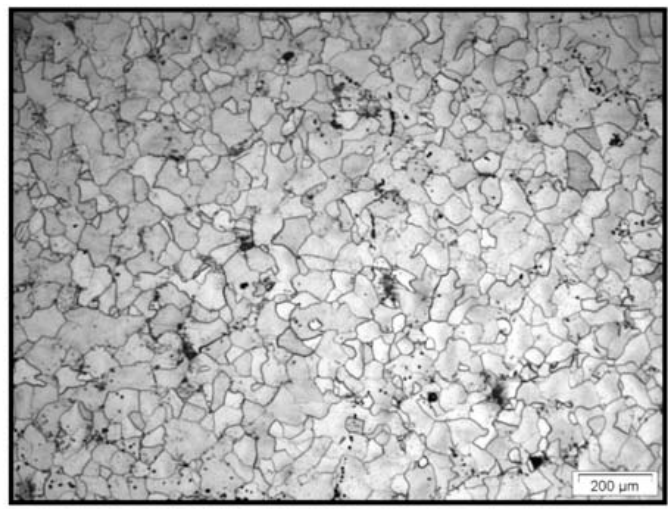

(b)

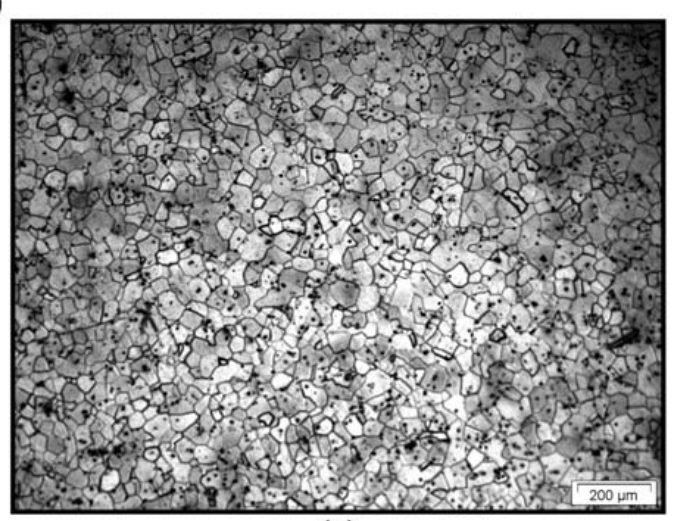

(c)

3 Microstructure of sintered samples following sintering in vacuum at $1100^{\circ} \mathrm{C}$ for 30 min: $a$ Ti45 as received powder; $b$ Ti10 spray dried powder without alumina; $c$ Ti10 spray dried powder with alumina addition
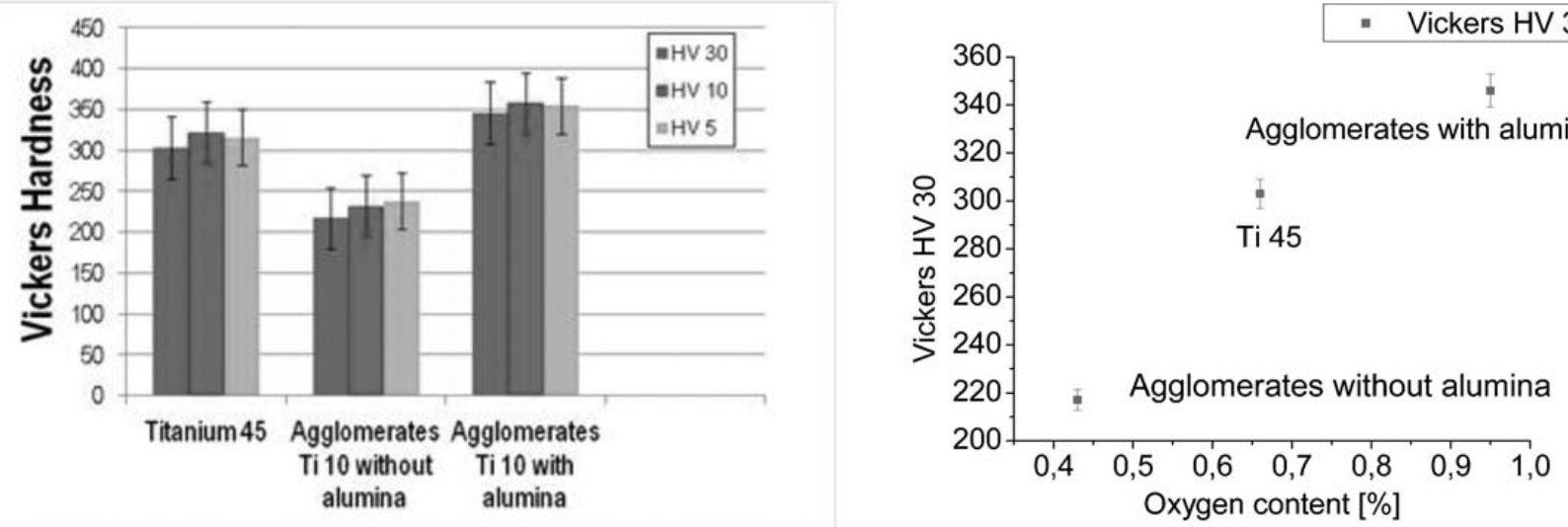

4 Vickers hardness of specimens sintered at $1100^{\circ} \mathrm{C}$ for $30 \mathrm{~min}$ and relationship between Vickers hardness and oxygen content

surfaces. The sprayed agglomerates range between 50 and $300 \mu \mathrm{m}$ in size.

The compressibility of the

agglomerates obtained from aqueous suspensions was better than titanium powder of particle size $45 \mu \mathrm{m}$.

Sintered specimens with density as high as $98 \%$ of theoretical were obtained at temperatures as low as $1100^{\circ} \mathrm{C}$ and sintering times of $30 \mathrm{~min}$

It was confirmed that the presence of alumina particles restrains grain

Table 2 Characteristics of sintered materials: relative density $\rho$, porosity $P$

\begin{tabular}{|c|c|c|c|c|c|c|c|}
\hline \multirow[b]{2}{*}{ Type of powder } & \multicolumn{2}{|c|}{ Relative density/\% } & \multicolumn{3}{|c|}{ Porosity/\% } & \multirow[b]{2}{*}{ O/wt-\% } & \multirow[b]{2}{*}{ Mean grain size $/ \mu \mathrm{m}$} \\
\hline & $\rho_{\text {pycnometer }}$ & $\rho_{\text {dimensions }}$ & $P_{\text {total }}$ & $P_{\text {open }}$ & $P_{\text {closed }}$ & & \\
\hline Agglomerated Ti10 & $96.02 \pm 0.001$ & $95 \cdot 18 \pm 0.01$ & $4 \cdot 82$ & 0.84 & 3.98 & 0.43 & 60 \\
\hline Agglomerated Ti10 with $\mathrm{Al}_{2} \mathrm{O}_{3}$ & $98 \cdot 74 \pm 0.001$ & $96 \cdot 29 \pm 0.01$ & $3 \cdot 71$ & 2,45 & $1 \cdot 26$ & 0.95 & 44 \\
\hline
\end{tabular}


growth during sintering, contributing to increased hardness.

\section{Acknowledgements}

The authors acknowledgement the financial support from Spanish Ministry of Science and Innovation through projects MAT 2009-14448-C01, and MAT 2009-14448-C02. This is an edited version of a presentation at Euro PM 2012, organised by EPMA in Basel, Switzerland on 16-19 October 2012.

\section{References}

1. I. J. Polmear: 'Light alloys. from traditional alloys to nanocrystals', 4th edn, 20-38; 2006, Oxford Butterworth Heinemann.

2. C. Leyems and M. Peters: 'Titanium and titanium alloys. fundamentals and applications', 2-18; 2003, Weinheim, Wiley-VCH.
3. P. G. Esteban, L. Bolzoni, E. M. Ruiz-Navas and E. Gordo: 'PM processing and characterisation of Ti-7Fe low cost titanium alloys', Powder Metall., 2011, 54, 242-252.

4. P. G. Esteban, E. M. Ruiz-Navas*, E. Gordo: 'Influence of Fe content and particle size the on the processing and mechanical properties of low-cost Ti-xFe alloys', Mater. Sci. Eng. A, 2010, 527, 56645669.

5. W. Wei, Y. Liu, K. Zhou and B. Huang: Powder Metall., 2003, 46 246-250.

6. D. Handtrack et al.: 'Fabrication of ultra-fine grained and dispersionstrengthened titanium materials by spark plasma sintering', Mater. Sci. Eng. A, 2006, 437, 423429.

7. D. Handtrack et al.: 'Microstructure and properties of ultrafine-grained and dispersion -strengthened titanium materials for implants', 2008, 43, 671-679.

8. D. Y. Hirata: 'Colloidal processing', Process. Colloid. Ceram., 1995, 25, 271-276.

9. A. J. Sanchez-Herencia: 'Water based colloidal processing of ceramic laminates', Key Eng. Mater., 2007, 333, 39-48.

10. B. Ferrari, A. J. Sanchez-Herencia and R. Moreno: 'Porous nickel coatings on steel tubes formed by aqueous colloidal processing', Adv. Eng. Mater., 2002, 4, 690694

11. I. Gonzalo-Juan, B. Ferrari, M. T. Colomer, and A. J. SanchezHerencia: 'Colloidal processing and sintering of porous percolative Ni-YSZ layers', J. Mem. Sci., 2010, 58, 3014-3021. 